\title{
Opinión
}

\section{Medicina darwiniana}

\author{
Carlos de Céspedes Montealegre
}

En 2009 se celebran 200 años del nacimiento de Charles Darwin y 150 años de la publicación de su libro El origen de las especies; es pregunta obligada por qué lo hizo a 50 años de edad, cuando aparentemente contaba con los elementos para hacerlo muchos años antes. De hecho, aunque no era inminente, existía el riesgo razonable de que se le adelantara en la primicia, un naturalista más joven, Alfred R. Wallace, quien había arribado a una idea muy similar acerca de la evolución biológica. Presentía el impacto que iba a tener y que de hecho tuvo en comunidades religiosas la idea de que el hombre no era el centro de la creación, sino un descendiente de otros seres vivos como los simios. Darwin sufrió durante toda su vida adulta de un extraño trastorno que algunos atribuyen a la carga emocional que le produjo su obra antes y después de publicada, una entre las posibilidades diagnósticas, que incluyen haber sido afectado por la enfermedad de Chagas durante su viaje a Sudamérica en el Beagle.

Es lamentable que los ataques a su teoría con posiciones dogmáticas persisten hasta nuestros días. Muchos confunden o quieren confundir evolución con ateísmo; es como si a estas alturas se calificara de antirreligiosos a quienes afirman que la Tierra se mueve. Los creacionistas o proponentes del "diseño inteligente" confunden la controversia inherente al progreso de la investigación científica con la debilidad de una teoría. No se entiende o no se quiere entender que prácticamente nunca se llega a comprobar una determinada teoría, sino que se aporta evidencia en favor o en contra. En el caso de la evolución por selección natural, la evidencia en favor es abrumadora: la paleontología, la embriología, la bioquímica y más recientemente el estudio del genoma humano y de otras especies, han reforzado las bases de esta teoría, de manera que puede considerarse un hecho. Existen, desde luego, preguntas sin contestar y seguirán surgiendo otras, precisamente porque esto es inherente al proceso de la investigación científica. Como señala Francis Collins en su excelente libro ¿Cómo habla Dios? ${ }^{1}$ se puede ser religioso sin ser fanático, ya que esas lagunas eventualmente pueden ser llenadas por la ciencia; los dogmáticos ponen a Dios a priori a llenar esos vacíos, lo cual interfiere con el progreso

Médico asesor ad honorem, Servicio de Genética y Metabolismo, Hospital Nacional de Niños "Dr. Carlos Sáenz Herrera"

Miembro de Número,ACANAMED

Director, CEC UCIMED

ISSN 0001-6002/2009/51/2/110-113

Acta Médica Costarricense, $\mathbb{C} 2009$

Colegio de Médicos y Cirujanos de la humanidad y perjudica la misma religión. La evolución por selección natural permite entender el mundo viviente que nos rodea y nos ofrece la oportunidad de utilizar sus principios para profundizar en la exploración del origen de las enfermedades y mejorar la salud humana.

La medicina evolucionaria o medicina darwiniana es la aplicación de la ciencia básica de la biología evolucionaria a la medicina.

Los dos fundamentos principales de la teoría de la evolución de Darwin son: - las especies evolucionan gradualmente y descienden de un ancestro común, y - el mecanismo de la evolución es la selección natural, definida como la conservación de variaciones que confieren valor adaptativo o ventaja selectiva (capacidad para reproducirse) y la eliminación de variaciones deletéreas (ej. abortos espontáneos). De acuerdo con la síntesis de la evolución con la genética en los años 30 y 40, conocida como Neodarwinismo, en una población determinada esas variaciones resultan de mutaciones (cambios en la secuencia de bases del ADN) al azar; la conservación de las que tienen beneficio selectivo está determinada por el ambiente (presión selectiva) al cual se adapta el individuo. La frase "survival of the fittest" no debe interpretarse necesariamente como "sobrevivencia del más fuerte", ${ }^{2}$ ni siquiera como el de mejor condición física, sino como "sobrevivencia del que tiene mayor valor adaptativo", o sea, mayor capacidad para generar descendencia.

A la pregunta de por qué la selección natural no ha eliminado del todo las enfermedades, inclusive enfermedades genéticas graves, la respuesta inmediata debe ser que más bien la enfermedad es un resultado de la misma selección natural, que progresivamente nos hace vulnerables, por las siguientes cinco razones:

\section{Reproducción a expensas de la salud}

La selección natural no diseña a los organismos para ser saludables; solo en el tanto en que la salud aporte al éxito reproductivo. Un gen que contribuye a lograr mayor progenie, se hará más común en la población, aun si causa enfermedad o muerte temprana (el salmón se reproduce una

\footnotetext{
${ }^{1}$ Título pobremente traducido del original "The Language of God"

${ }^{2}$ Esto inclusive llevó a la idea del llamado "darwinismo social", que es una usurpación perversa del verdadero darwinismo, por Spencer $y$ otros.
} 
vez y muere). Un gen que disminuye la reproducción será eliminado aun si aumenta la sobrevida del individuo. La crudeza de la selección natural es claramente ilustrada por Richard Dawkins en su obra The Selfish Gene, con la metáfora de que los organismos son vehículos que ayudan a los genes a maximizar la transmisión de información genética, independientemente del impacto resultante en los individuos o en la sociedad.

El inexorable proceso de la senescencia y sus enfermedades acompañantes se comprende mejor a la luz de la evolución, mediante la probable acción de genes pleiotrópicos (que tienen más de un efecto), como propone George C. Williams. El frenesí reproductivo inherente a la selección natural conduce a genes que aumentan el valor adaptativo en la edad reproductiva, a mostrar efectos deletéreos en la edad postreproductiva (pleiotropía antagonista). Por ejemplo, a un gen que favorezca la asimilación de calcio para lograr huesos más fuertes en la juventud, "no le interesa" que esa misma capacidad resulte a edades mayores en el depósito de ese elemento en las arterias coronarias, diseñadas con un calibre apenas suficiente para los fines de la selección natural. Los mecanismos de reparación del $\mathrm{ADN}$, la capacidad antioxidante para neutralizar los radicales libres y el consiguiente daño celular, requieren energía. Nuevamente, al organismo "no le interesa" invertir en el mantenimiento de la integridad celular después del pico reproductivo. Esta es otra explicación evolucionaria de la senescencia -no excluyente de la anterior- así como de las enfermedades degenerativas que acompañan este proceso. En el caso del cáncer, los mecanismos responsables de controlar la división celular también tienden a debilitarse con la edad. Es más bien admirable que estos mecanismos de control mantengan "a raya", en la mayor parte de la vida, la tendencia de las células a malignizarse, ya que las cancerosas, en su multiplicación acelerada, simplemente siguen el mandato de la selección natural: "reproducíos al máximo".

Patógenos coevolucionan con hospederos. Es notable que aunque la idea de la medicina darwiniana empezó apenas en los 80 , ya esté dando sus frutos, sobre todo en el campo de las enfermedades infecciosas. La resistencia bacteriana a los antibióticos y la transmisión de bacterias y virus, solo puede entenderse y tratar de solucionarse con un enfoque evolucionario. El concepto de virulencia, desarrollado por Paul Ewald, explica por qué agentes infecciosos como bacterias o virus resultan más agresivos y difíciles de tratar si son transmitidos por vectores como artrópodos, personal de salud en hospitales, jeringas, o bien, de persona a persona, como ocurre con el virus del resfriado común, en el que la virulencia tiende a ser menor. Al igual que depredadores como los coyotes y presas como los conejos, los patógenos y sus hospederos como los humanos y sus ancestros, han coevolucionado durante millones de años, desarrollando estrategias y contraestrategias para sobrevivir y reproducirse.
De hecho, la "supervivencia del mejor adaptado", en la que los patógenos pueden evolucionar a velocidades miles de veces mayores que los humanos, explica el motivo por el que no es sostenible la hipótesis de que parásitos y hospederos evolucionan hacia una coexistencia feliz.

Nuestro sistema inmune (IgE) tuvo que activarse fuertemente durante millones de años. Como la evolución es característicamente lenta, esta condición persiste en un ambiente más higiénico, producto de intervenciones en salud pública y tratamientos médicos. El resultado es que los patógenos son sustituidos por las células del hospedero como objetivos del ataque inmunológico, supuestamente dando origen a alergias, asma, enfermedades autoinmunes y aun leucemias. La propuesta en estudio, inspirada en esta hipótesis evolucionaria, de inmunizar con proteínas de helmintos para atraer la atención del sistema inmune hacia su objetivo original, es razonable y prometedora.

Discordancia genético-cultural. Nuestro genoma prácticamente es el mismo de cuando los humanos eran cazadores-recolectores y aparentemente desarrollaron "genes ahorrativos", que determinaban un apetito voraz por el azúcar, la grasa y la sal, muy escasas en el período paleolítico; hoy, 10000 años después del desarrollo de la agricultura, persiste ese apetito, ante la abundancia y una vida sedentaria. El resultado es la pandemia de obesidad con sus consecuencias: diabetes e hipertensión.

Este conocimiento, aunque refuerza el argumento de mejorar la dieta y aumentar la actividad física, no nos ha llevado directamente a un mejor control de estas "enfermedades de la civilización"; nos alerta, sin embargo, del peligro de utilizar el conocimiento sobre el genoma humano para manipularlo, ya que la persistencia en la población de genes que provocan enfermedades serias, o sea, que no han sido eliminados por la selección natural, se explica porque pueden tener algún beneficio no reconocido. De hecho no existe un genoma humano normal. Esto se ilustra con el ejemplo de la anemia de células falciformes, en que el paciente (homocigoto) hereda dos copias del gen que determina la síntesis de la hemoglobina S. Esta anemia es el precio de cierta protección contra la malaria, en individuos clínicamente normales y cuarenta veces mayor en número, que llevan una sola copia de este gen (heterocigoto). La terapia génica es la esperanza para curar a los enfermos que sufren de esta severa anemia. La selección natural nos advierte, sin embargo, del resultado funesto de aplicar esta receta a los heterocigotos, dejando desprotegidos contra la malaria a gran número de individuos, sobre todo en poblaciones africanas.

Restricciones, compromisos de diseño y concesiones. Es un error creer que los humanos evolucionan hacia la perfección. Si fuera así no estaríamos dependiendo del cierre de la glotis, para no morir asfixiados por un trozo de carne. En el ojo humano la retina está invertida en su posición; el 
nervio óptico por fuera (ej. en el calamar) no provoca el punto ciego y fijaría mejor el globo ocular, con menor riesgo de desprendimiento de la retina. La selección natural no tiene dirección ni propósito, más bien su limitado accionar parece ser el resultado de un trabajo en cierto modo "al tanteo", ya que únicamente diseña a los organismos para que se adapten a un determinado nicho ecológico. La selección natural no puede empezar de novo, simplemente va "esculpiendo" las nuevas especies, sobre las estructuras de las precedentes.

El bipedalismo, por ejemplo, nos predispone a los problemas de columna vertebral, al frecuente lumbago, así como a la dificultad única del parto en el humano; estos son ejemplos de las restricciones y concesiones que impone la selección natural, ya que una ventaja adaptativa: poder utilizar las manos, tiene su precio; en el otro caso, con la pelvis restringida por la posición erecta, se presenta una desproporción con el tamaño de la cabeza del feto, precio que se paga por un mayor desarrollo cerebral.

Síntomas como defensas. La tos, el vómito, la diarrea, la fiebre, el dolor y aun emociones como la ansiedad, son mecanismos útiles de defensa desarrollados por la selección natural, pero como esta no es perfecta ni mucho menos, algunos de tales mecanismos se pueden desregular y convertirse en una amenaza para la salud y la vida. Se requiere investigación a la luz de la selección natural, para llegar a saber cuándo es seguro bloquear estas defensas, que generalmente no se consideran así en la práctica médica, menos en la propaganda de medicamentos de libre venta. El hecho de que no haya mayores consecuencias obedece a que el organismo tiene mecanismos redundantes de protección y a que estas defensas no están finamente sintonizadas con las amenazas; la mayoría de las veces son falsas alarmas, el mismo principio del defector de humo. Un ejemplo más difícil de apreciar como defensa es la anemia que acompaña a una infección. La ecuación en niños desnutridos severos con un cuadro infeccioso, anemia $\rightarrow$ tratamiento con hierro, resulta en agravamiento de la infección y aun en la muerte, ya que el hierro es nutriente preferido de las bacterias. Con un enfoque evolutivo, se entiende que la anemia es un mecanismo adaptativo de defensa del cuerpo humano en su coevolución con los patógenos, al secuestrar el hierro en ciertas células, fuera del alcance de las ávidas bacterias. Uno de los propósitos de la medicina darwiniana es buscar otros ejemplos de manifestaciones de enfermedad que han evolucionado como una defensa y no como un problema.

La selección natural no procesa los conceptos de justicia o moral. Se debe despejar un posible malentendido, en tanto el enfoque evolucionista no significa que debemos resignarnos a la enfermedad, sino que más bien nos ayuda a entenderla, y a mejor tratarla y evitarla. Para derrotar al "enemigo" se deben descubrir sus secretos. La medicina darwiniana no es una panacea y aunque hemos citado algunos ejemplos de su aplicación a la medicina y la salud pública, su valor en la actualidad es heurístico. La medicina darwiniana no pretende sustituir la investigación biomédica actual (proximal, Cuadro 1), sino complementarla. Es preciso considerarla la ciencia más básica de la medicina, que permite dar coherencia a la diversidad de datos, resultado de la investigación en áreas cada vez más especializadas. Someter a prueba hipótesis evolucionarias sobre la enfermedad, presenta dificultades particulares al tener que tomar en cuenta el componente histórico, aunque este esfuerzo se ha enriquecido recientemente con enfoques experimentales, utilizando como herramientas la ingeniería genética y modelos matemáticos.

Al igual que otras ciencias básicas de la medicina, como la bioquímica, la biología molecular y la genómica, la medicina darwiniana no puede ofrecernos a menudo aplicaciones inmediatas. Ofrece desde ahora, sin embargo, un marco de referencia integrador de la cantidad de datos dispersos que resultan de la investigación especializada en esas y otras disciplinas, lo que abruma al estudiante y al practicante. En cuanto a la enseñanza, no parece recomendable agregar un curso aislado al ya sobrecargado currículum de la carrera. Sería más productivo integrar el enfoque evolucionario con las materias básicas y clínicas existentes, donde se considere más apropiado. En la práctica clínica, después de entender bien sus principios, se pueden utilizar para explicar mejor una patología a los pacientes (Cuadro 2), lo que en algunos casos ayudaría a cumplir con el principal mandato de la medicina: "consolar siempre".

\section{Referencias}

1. Why We Get Sick. The New Science of Darwinian Medicine, Randolph M. Neese y George C. Williams

2. Darwin's Gifts. The Lancet. Número especial, diciembre 2008
Cuadro 1. Explicaciones proximales y evolucionarias en biología y medicina

La famosa frase del prominente biólogo Theodosius Dobzhansky, "Nada tiene sentido en biología si no es a la luz de la evolución" se puede aplicar con certidumbre a "Nada tiene sentido en medicina si no es a la luz de la evolución". El estudio de una característica de un ser viviente, anatómica o funcional, de un comportamiento o de una enfermedad, está incompleto si no se somete a la pregunta de si tiene alguna explicación evolucionaria, esto es si tiene relación con sus ancestros (filogenia) o si confiere o no ventaja selectiva.

Refiriéndonos aquí al caso de la enfermedad, el Paradigma Médico Tradicional ha considerado que todos los individuos son igualmente susceptibles a factores ambientales (extrínsecos). El Paradigma Genético de la Salud y la Enfermedad reconoce la participación defactores genéticos (intrínsecos) además de los ambientales. Estos dos paradigmas representan la explicación proximal o inmediata (¿cómo?) de una enfermedad. El Paradigma Evolucionario contempla la filogenia y el valor adaptativo, la explicación última (¿por qué?). 


\section{Cuadro 2. Ictericia neonatal: ¿patología o adaptación evolucionaria que puede desregularse?}

La biliverdina es un producto soluble de la degradación del heme. ¿Por qué entonces no se elimina por el riñón sin necesidad de utilizar energía para transformarla en bilirrubina y nunca haber conocido el kernicterus? Resulta que la bilirrubina es un potente antioxidante y se ha demostrado experimentalmente que neutraliza radicales libres. La hipótesis desde el punto de vista darwiniano es si la hiperbilirrubinemia podría ser una defensa contra el daño tisular en un recién nacido mientras maduran sistemas enzimáticos antioxidantes como la catalasa y la superóxido dismutasa. A la pregunta de si es algo protector por qué se dispara en no pocas ocasiones hacia niveles tóxicos para el sistema nervioso central, la respuesta es que la selección natural no puede diseñar mecanismos que puedan regular finamente las defensas (Ver "Síntomas como defensas" en el texto principal).

El nivel "fisiológico" de bilirrubinemia en el recién nacido sigue siendo objeto de debate. Debe realizarse investigación, sin embargo, para valorar si la fototerapia en ictericias leves es una medida prudente ante el riesgo de que el niño llegue a desarrollar kernicterus o si es una medida desaconsejable porque se está bloqueando un mecanismo de defensa, elegante pero torpemente diseñado por la selección natural, contra daños a la membrana celular. Esto adquiere mayor relevancia ante la posibilidad de inducir deficiencia de riboflavina (vit. $\mathrm{B}_{2}$ ) que es particularmente fotosensible. Con las reservas del caso, desde ahora se puede explicar a una madre angustiada por qué su hija Juanita a los pocos días de nacida se puso amarillita; contra sus temores su hija no sólo no ha estado enferma sino que ha estado más protegida que Pablito el vecino de cuna que no se puso amarillo del todo, ante la tranquilidad de su madre y la envidia hacia ésta de la mamá de Juanita.

\section{Cuadro 3. Lo que NO es la medicina darwiniana}

- $\quad$ No es una forma alternativa de atención médica como la homeopatía o la medicina tradicional china.

- $\quad$ No es una fuente de curas rápidas.

- No está precisamente para evitar tratamientos con medicamentos.

- $\quad$ No es un enfoque específico.

- $\quad$ No pretende servir de guía a decisiones morales ni a la forma en que los médicos deben practicar la medicina.

- $\quad$ No acepta, más bien rechaza vehementemente al equivocado y perverso "darwinismo social" y a la desacreditada eugenesia.

- No pretende probar o descartar asuntos teológicos, como la existencia de un Ser superior.

\section{Comité Editorial Acta Médica Costarricense}

\begin{tabular}{ll}
\hline Lista de revisión para autores & Artículo (a doble espacio) \\
Por favor, complete esta lista antes de enviar su manuscrito. & $\square$ Carta de aprobación del estudio por Comité Ético - científico \\
$\square$ Carta de presentación & $\square$ Resumen estructurado en español \\
$\square$ Tres copias completas del manuscrito con cuadros y figuras, y & $\square$ Resumen estructurado en inglés \\
$\quad$ en formato digital & $\square$ Introducción \\
$\quad$ Página de título & $\square$ Materiales y métodos \\
$\square$ Título & $\square$ Resultados \\
$\square$ Título corto, no mayor de 45 caracteres & $\square$ Discusión \\
$\square$ Autor(es) y afiliación(es) & $\square$ Agradecimientos y colaboradores \\
$\square$ Lugar donde se realizó el trabajo & $\square$ Referencias \\
$\square$ Descriptores en español e inglés & $\square$ Cuadros, leyendas de las figuras, figuras \\
$\square$ Abreviaturas & $\square$ Permiso para reproducir todo material previamente publicado y \\
$\square$ Dirección, teléfono y número de fax del autor a quien se debe & autorización de pacientes para publicar fotografías \\
$\quad$ dirigir toda correspondencia & $\square$ Carta de cada autor de asignación de derechos, responsabilidad \\
$\square$ Fuentes de apoyo y manifestación de conflictos de interés & de participación y declaración de financiamiento, si existiera \\
& (puede ser una, firmada por todos los autores).
\end{tabular}

